\title{
Water intake fees as an instrument for sustainable water resources management
}

\author{
Krzysztof Berbeka \\ Cracow Univeristy of Economics, Rakowicka Street 27, 31-210 Kraków, e-mail: krzysztof.berbeka@uek.krakow.pl
}

\begin{abstract}
The main target of this paper is to develop the hypothesis that water intake fees can be an efficient tool for the management of water consumption in Poland. The sample used in the research consists of 600 municipal water operators with a market share over $80 \%$ in the municipal sector. The analysis comprises several tasks: firstly - the investigation of the relation between water intake fees and the structure of the costs of water provision; secondly - the investigation of the influence of fees on unit prices and a review of their changes over the last decade; and, thirdly - the analysis of demand elasticity in order to estimate demand reaction. The results obtained give an estimation of possible savings in water usage in Poland that would result from changes in the system of water intake. The analysis includes all the mechanisms of fee reductions, or exemptions for certain purposes, of existing water intake in Poland. This analysis compiles, compares and processes incremental results from several pieces of research led by the author over the last 10 years for the Ministry of the Environment the National and Regional Water Boards and also for the Institute for Meteorology and Water Management. Research was focused on the economic analysis of water usage from a more general view, however, water intake fees are taken into account in these papers, although not as separate targets for investigations.
\end{abstract}

Key words: sustainable management of water resources, water intake fees, efficiency of fees.

\begin{abstract}
Abbreviations: CSO - Central Statistical Office, $\mathrm{hm}^{3}$ - cubic hectometer, IGWP - Polish Chamber of Water Operators, WFD - Water Framework Directive
\end{abstract}

Submitted 15 April 2013, received 27 May 2013, accepted 12 November 2013

\section{Introduction}

The main target of this paper is to develop the hypothesis that water intake fees can be an efficient tool for the management of water consumption in Poland. Demand management appears an alternative instrument for balancing increasing water needs. Another option - an increase in the water supply - cannot be applicable in all cases, especially due to the high increase in demand and changes in available resources caused by global climate change. Therefore demand management can serve as an alternative tool for balancing needs with resources. Answering the question of how efficient such an instrument can be, not only in qualitative terms but also in a stricter way, using quantitative instruments, was much more challenging.

The paper consists of the following chapters: the first one describes the research sample, sector and the period of investigation. The second focuses on the research methodology and basic assumptions. The third part presents the results of calculations. The last chapter includes the development of the main hypothesis and more general conclusions related to the possibilities of using intake fees for demand management.

\section{Research area and period}

The research is limited to the municipal sector only. A rough review of the breakdown of water consumption by sector of economic activity indicates that the munici- pal sector is not the most important (see Fig. 1). However, more detailed analysis indicates that the dominant position of the industrial sector is not sufficiently justified. In this sector $90 \%$ of water intake was for cooling purposes, with immediate discharge into the intake sources without changes in water quality ${ }^{1}$. As a result, such intake will not change the general water balance. After exclusion of water intake for cooling purposes, the breakdown of water consumption between the major sectors appears very different. In this modified calculation the municipal sector is responsible for more than half of all water intake, and is therefore the most important sector when discussing water balance.

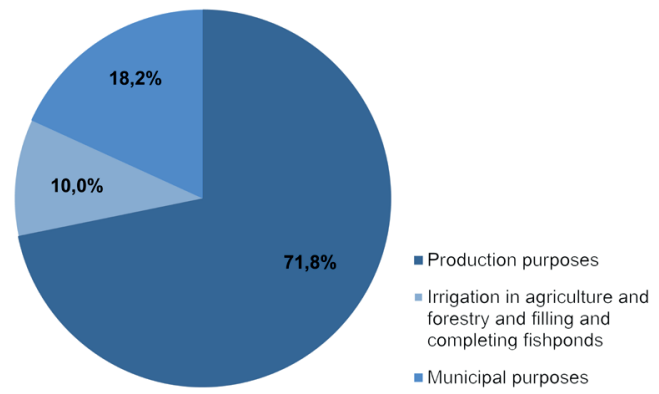

Figure 1. Breakdown of water intake between main sectors in Poland in 2011 (source: Environment protection 2012, Central Statistical Office, Warsaw 2012)

The research focused on the municipal sector only, due to the more pragmatic reasons related to the present legal

1) in very limited cases the water temperature significantly increased 


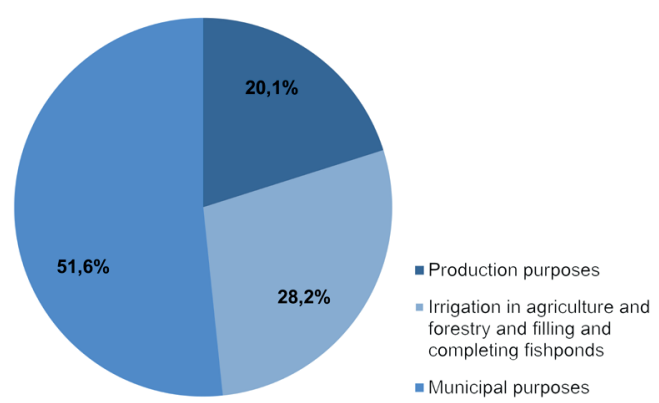

Figure 2. Modified breakdown of water intake between main sectors in Poland in 2011 (source: Environment protection 2012, Central Statistical Office, Warsaw 2012)

status of intake fees. Water withdrawal for agricultural irrigation is exempted from such fees ${ }^{2}$, and is therefore not so sensitive to these economic factors. In the case of industrial activity, the costs incurred from water intake fees are very limited within the wider cost structure. The figures justifying this statement are provided in the empirical chapter, and are compared to the municipal sector.

The importance of water intake fees in cost structures was researched using a questionnaire interview given to the whole sample of municipal water operators in Poland. Such a series of investigations has been made only twice previously in Poland - by Regional Water Authorities for the purposes of economic analysis, as required by the Water Framework Directive. Water intake fees are not subject to annual, permanent investigation by the Central Statistical Office or branch chamber (Polish Chamber of Water Operators). Therefore, the most comprehensive data is gathered by the Regional Water Authorities. Furthermore, due to the obligation to repeat the research for selected regions, two sets of data are available - data from 2006 (all Authorities), and from 2010 (3 of 7 Authorities finished

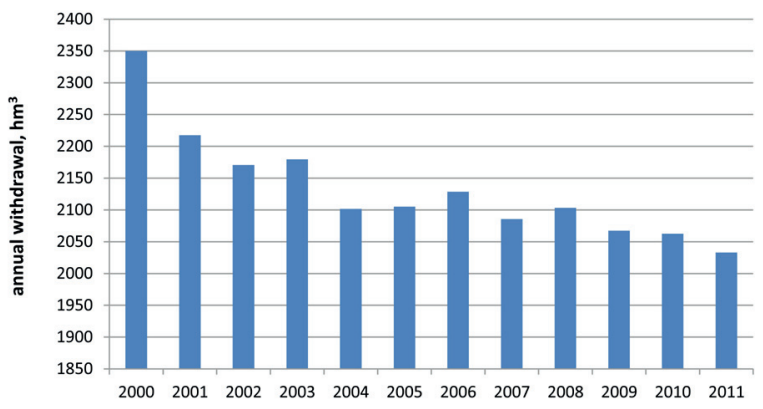

Figure 3. Annual withdrawal for municipal purposes in Poland (source: Yearbooks Environment Protection for each year 20002011, CSO, Warsaw)

the second round of calculation). For the selected sample (still over 500 operators), dynamic observations are possible. The sample of water operators used for calculation is summarized in Tab. 1.

It's fairly difficult to assess the demand pressure in municipal water provision. This market is influenced by several, opposing factors related to water consumption. A review of the main factors is presented in Tab. 2.

As a result of the combination of the above factors, the water intake for municipal purposes appears to drop over the last 10 years (Fig. 3).

The decrease in water demand presented in the above diagram should be considered alongside the main factors from Tab. 2. The increase of inhabitants with access to piped water was not substantial in the period 2000-2011 (growth ranged at $1.9 \%$ ). The price for water provision increased during the same period by $237 \%$ (mean) and $239 \%$ (average). This is probably the main factor affecting the fall in water intake. Such an effect indicates the potential for managing demand by controlling pricing.

Table 1. Description of the sample of water operators in Poland used in the research sample

\begin{tabular}{|c|c|c|c|}
\hline & Unit & 2006 & 2010 \\
\hline Number of operators in the sample & - & 1253 & 647 \\
\hline Amount of water intake (by entities from the research sample) & $\mathrm{hm}^{3}$ & 1575 & 576 \\
\hline $\begin{array}{l}\text { Percentage of water intake by operators from research sample in com- } \\
\text { parison to the total water intake by the municipal sector in Poland }\end{array}$ & $\%$ & $74.0 \%$ & $28 \% / 86.5 \%{ }^{1)}$ \\
\hline
\end{tabular}

1) data from 3 Regional Water Authorities - the first value refers to the total water withdrawal in Poland, the second to the withdrawal by Authorities covered by the research sample

Source: Own calculation

Table 2. Review of the factors influencing water consumption in municipal services

\begin{tabular}{|l|l|}
\hline \multicolumn{1}{|c|}{ Factors boosting water consumption } & \multicolumn{1}{c|}{ Factors mitigating water consumption } \\
\hline Increase in population connected to water pipelines & Permanent increase of prices \\
\hline Growth of the welfare level & $\begin{array}{l}\text { Shift in methods of charging for water consumption - from flat rate to } \\
\text { volumetric tariffs }\end{array}$ \\
\hline Lack of proper supervision concerning water losses & $\begin{array}{l}\text { Migration of the population to Western Europe (in official statistics, the } \\
\text { majority of such people still live in Poland) }\end{array}$ \\
\hline Increasing trend of subsidizing water provision by municipalities & \\
\hline
\end{tabular}

\footnotetext{
2) More strictly: intake of surface water for irrigation is exempted from intake fees, but withdrawal of ground water for such purposes is generally prohibited in Poland
} 


\section{Research methodology and basic assumptions}

The verification of the hypothesis concerning the possibility of using intakes fees for the management of water demand will be processed using a scheme consisting of 5 steps (Fig. 4).

- Modification of the unit intake fees

- Changes of unit costs of water supply (caused by changes of intake fees)

- Changes of the prices/tarrifs of water

- Demand reaction caused by changes of the tarrifs

- Change of water intake as a result of changes of the demand for water

Figure 4. Main steps of calculations

Due to the comprehensive research made for the purposes of economic analysis, it is possible to gather the average water unit intake fees, and also the extreme cases (min, max). Furthermore, due to the knowledge of unit costs of water provision in each operator, the share of water intake costs in terms of total costs is known (in several formats - average, weighted average, mean, $\min , \max ^{3)}$ ).

The process of modeling the influence of the modification of unit fees on the costs of water provision is a little more complicated. This is due to the necessity of including within the calculations both the processes of water loss during distribution and also water consumption for technical purposes. The statistical description of these specified effects can result in a multiplying effect of increasing the unit fee on the unit costs. This is caused by the fact that for the provision of $1 \mathrm{~m}^{3}$ of water to a client, it is necessary to withdraw approx. $1.3 \mathrm{~m}^{3}$ of water. This mechanism is investigated in Tab. 4 of this chapter. As a result, a detailed relation between unit costs and unit fees is established.
The next step (step 3 in Fig. 4) requires a review of the possibility of the transmission of costs to prices. Due to the detailed analysis of cost recovery by each operator, such activity was indeed possible. Some special constraints are applicable due to the increasing effect of the subsidizing of water provision activity by the municipalities. The general requirements of WFD are related to the minimum full cost recovery at the financial level. This means that the prices should reflect all costs. The investigation made using data from both 2006 and 2010 indicates that the sector as a whole meets such requirements. The financial rate of return for water provision in municipal sector ranges from: a) in $2006-104.7 \%$,

b) in $2010-103.7 \%$ (weighted average, for 3 Water Authorities).

The estimation of demand reaction appears to be the most subjective part of the research. It is necessary to assume a demand price elasticity coefficient for Polish circumstances. This coefficient is not obvious and several different results have been published. Furthermore, only one piece of research was identified in Poland for medium and large agglomerations: Bartczak et al. (2009). The final results of that project indicate the value of price elasticity equals -0.22 . The value used in previous calculations aimed at reviewing the consequences of the introduction of EU environmental related directives in Poland was quite similar - 0.20 Berbeka (2003). A short comparison of other European studies is presented in Tab. 3.

The European studies presented above are roughly consistent, however one of the most comprehensive comparisons (Espey 1997), which focused on data from the United States, indicates the average value -0.51 . This is the result of 24 reviewed papers that yielded 124 estimates of the price elasticity of the demand for residential water usage in the United States. Taking into account the local level of the calculation, the results from the USA were skipped and for the present calculation the value -0.22 was taken as the best available estimation.

Table 3. Review of empirical European studies aimed at estimation the demand price elasticity index for water

\begin{tabular}{|l|l|l|l|l|}
\hline Country & Model & Period & Value & Source \\
\hline Denmark, Copenhagen & TS/OLS & & $-0,1$ & Hansen (1996) \\
\hline France, 116 Eastern provinces & CS-TS/Panel & $1988-1993$ & AP, s/r:-0.22 & Nauges \& Thomas \\
Gironde & & & AP, $1 / \mathrm{r}:-0.26$ & MP, s/r:-0.18 \\
& CS/OLS & & $-0,17$ & \multirow{2}{*}{ Point (1993) } \\
& & & -0.24 & Critelli (1998) \\
\hline Italy, area not defined & CS & 90 & AP, $1 / \mathrm{r}:-0.20$ & Höglund (1997) \\
\hline Sweden, 282 of 286 provinces & CS-TS/Panel & $1980-92$ & MP, $1 / \mathrm{r}:-0.10$ & \\
\hline
\end{tabular}

Key: TS - time series, OLS - method of least squares, CS - cross-sectional study, Panel - panel research, $1 / \mathrm{r}-$ long run, s/r - short run, AP - average prices, MP - marginal prices

Source: Household Water Pricing in OECD countries (1998), Working Party on Economic and Environmental Policy Integration, OECD, and M. Rouleau, (1994) A Review of Literature on Economic Instruments Affecting Water and Wastewater Flows, Environmental PROBE

\footnotetext{
3) The extreme values have been reviewed and skipped. The very low values come from wholesale of water from other operators (who pay intake fees). The very high values are results of contravention of permits for water intake or lack of such permits. Such situations exist, but are rare
} 
The final step of the calculation is similar to the second one. The same relation between water sold and water withdrawal was used, but this time in the opposite direction (the decrease in consumption caused the highest decrease in intake). The ratio of water sold/water withdrawal in Poland estimated using CSO data from the environmental yearbook for the period 2000-2001 is the following:

For the purposes of the calculation, the data from 2011 will be assumed as the best available estimation. Data presented in the table above leads to the following two conclusions:

a) the ratio of water loss and consumption for technical purposes $^{4}$ is constant, which means that in Poland there do not exist any sufficient, effective incentives to limit this process

b) the water intake fees in their present state are definitely not sufficiently strong (i.e. not sufficiently high) to reduce loss and technical consumption.

Finally, the estimation of the hypothetical water savings was made, taking into consideration a wide level of changes in unit fees, including some not very realistic changes.

The summary of basic data describing the municipal sector in Poland used for the modeling is described in Tab. 5.

\section{Results}

The share of water intake fees in the total cost of water provision seems to be decreasing. The results from the research mentioned here (provided by the Water Authorities) are summarized in Tab. 6. All average values given as a weighted average.

Furthermore, the earlier investigation conducted by the Ministry of Environment indicates that in 2002 the average share ranged at $4.2 \%$ and the average unit fee at $0.070 \mathrm{zl} / \mathrm{m}^{3}$ - Economic Analysis (2003). In monetary terms, the unit fee is quite stable which is consistent with two contrasting factors: (1) there is an annual mechanism for the valuation of such fees - according to an index of price changes (2) the share of fees which are doubled or tripled due to the lack of valid intake permits has decreased. As a result, an average fee in $1 \mathrm{~m}^{3}$ of sold water in currency is constant. In contrast to the changes in unit fees, the total cost of water provision has risen dramatically over time. The weighted average price (which more or less reflects the cost) has risen from $1.55 \mathrm{zt} / \mathrm{m}^{3}$ in 2000 to $3.70 \mathrm{zt} / \mathrm{m}^{3}$ in 2012. This is an increase of $239 \%$, and in result of such rapid changes the importance of intake fees fell within the wider view of total cost. The share of intake fees in total cost is still the highest among the subsectors of economic activity in Poland. For example in mining it is $0,009 \%$, in Industrial processing $0.0064 \%$, in Construction $0.0011 \%-$ Analysis of the policy of water charges (2009).

The influence of a hypothetical increase of water intake fees on the average unit cost of water provision is presented in Tab. 7.

According to the proposed methodology, the next step was focused on modeling the new prices to reflect the hypothetical changes of the unit intake fees. Using the assumption regarding full cost recovery and an average factor of financial rate of return at the level of $103.7 \%$, the forecast of new prices is presented in Tab. 8 .

The results of the final calculations are presented in Tab. 9. The expected demand reaction seems to be very limited.

Table 4. Changes of the ratio of water provided/water intake over period 2000-2011 in Poland

\begin{tabular}{|l|c|c|c|c|c|c|c|c|c|c|c|c|}
\hline & 2000 & 2001 & 2002 & 2003 & 2004 & 2005 & 2006 & 2007 & 2008 & 2009 & 2010 & 2011 \\
\hline $\begin{array}{l}\text { Ratio of water sold /water } \\
\text { withdrawal, \% }\end{array}$ & 74.6 & 75.4 & 74.9 & 76.0 & 76.1 & 75.4 & 75.3 & 75.4 & 75.1 & 74.7 & 74.7 & 76.0 \\
\hline $\begin{array}{l}\text { Necessary water withdrawal for } \\
\text { provision of } 1 \mathrm{~m}^{3} \text { water to clients } \\
\mathrm{m}^{3} / 1 \mathrm{~m}^{3}\end{array}$ & 1.34 & 1.33 & 1.33 & 1.32 & 1.31 & 1.33 & 1.33 & 1.33 & 1.33 & 1.34 & 1.34 & 1.32 \\
\hline
\end{tabular}

Source: Own estimation based on CSO data from Environmental Yearbooks 2001-2012

Table 5. Summary of main data describing the municipal sector in Poland

\begin{tabular}{|l|c|c|}
\hline & Unit & Value \\
\hline Average price of water (for households), 2010, net & $\mathrm{z} / \mathrm{m}^{3}$ & 2.93 \\
\hline Average cost of water provision, 2010 & $\mathrm{z} / \mathrm{m}^{3}$ & 2.98 \\
\hline Financial rate of return in water supply, 2010 & $\%$ & 103.7 \\
\hline Ratio of water sold /water withdrawal, 2011 & $\%$ & 76 \\
\hline Demand price elasticity index for water & - & -0.22 \\
\hline Annual water consumption per capita, 2011 & $\mathrm{m}^{3} /$ person/y & 31.5 \\
\hline
\end{tabular}

Source: data processed from Water Authorities investigation, price elasticity from Bartaczak et al. (1999), water consumption from CSO, Yearbook Environment Protection (2012)

\footnotetext{
4) The extreme values have been reviewed and skipped. The very low values come from wholesale of water from other operators (who pay intake fees). The very high values are results of contravention of permits for water intake or lack of such permits. Such situations exist, but are rare
} 
Table 6. Review of the cost of water intake fees in total cost of water provision in 2006 and 2010

\begin{tabular}{|c|c|c|c|c|}
\hline \multirow{2}{*}{$\begin{array}{c}\text { Water } \\
\text { Authorities }\end{array}$} & \multicolumn{2}{|c|}{ Share of intake fees in total cost of water provision, $\%$} & \multicolumn{2}{|c|}{ Average unit intake fee in $1 \mathrm{~m}^{3}$ of sold water, $\mathrm{z} t / \mathrm{m}^{3}$} \\
\hline & 2006 & 2010 & 2006 & 2010 \\
\hline Gdańsk & $3.21 \%$ & $2.20 \%$ & 0.065 & 0.059 \\
\hline Gliwice & $1.20 \%$ & nd & 0.042 & nd \\
\hline Kraków & $2.79 \%$ & 2.62 & 0.075 & 0.081 \\
\hline Poznań & $3.27 \%$ & nd & 0.079 & nd \\
\hline Szczecin & $2.51 \%$ & $1.98 \%$ & 0.050 & 0.054 \\
\hline Warszawa & $3.29 \%$ & nd & 0.067 & nd \\
\hline Wrocław & $3.18 \%$ & $\mathrm{~N}$ & 0.075 & nd \\
\hline
\end{tabular}

Source: Economic Analysis... (2009), tab. 17 and 18; Economic analysis (2012a, b, c)

Table 7. The influence of the changes in unit intake fees on the cost of water provision

\begin{tabular}{|c|c|c|c|c|}
\hline $\begin{array}{c}\text { Changes of } \\
\text { unit fees, } \%\end{array}$ & $\begin{array}{c}\text { Changes of unit charges } \\
\text { related to intake fees, } \%\end{array}$ & $\begin{array}{c}\text { Value of unit intake fee } / 1 \mathrm{~m}^{3} \\
\text { of provided water, } \mathrm{z} / \mathrm{m}^{3}\end{array}$ & $\begin{array}{c}\text { Modified unit cost of } \\
\text { water provision, zz/ } / \mathrm{m}^{3}\end{array}$ & Intake fee as \% of total cost \\
\hline $10 \%$ & $13.2 \%$ & 0.078 & 2.91 & $2.69 \%$ \\
\hline $30 \%$ & $39.6 \%$ & 0.096 & 2.93 & $3.29 \%$ \\
\hline $50 \%$ & $66.0 \%$ & 0.115 & 2.94 & $3.89 \%$ \\
\hline $100 \%$ & $132.0 \%$ & 0.160 & 2.99 & $5.35 \%$ \\
\hline $150 \%$ & $198.0 \%$ & 0.206 & 3.04 & $6.77 \%$ \\
\hline $200 \%$ & $264.0 \%$ & 0.251 & 3.08 & $8.15 \%$ \\
\hline $300 \%$ & $396.0 \%$ & 0.342 & 3.17 & $10.79 \%$ \\
\hline
\end{tabular}

Source: own estimation

Table 8 . Increase in the final price of water caused by changes in water intake fees

\begin{tabular}{|c|c|c|c|}
\hline $\begin{array}{c}\text { Changes of } \\
\text { unit fees, } \%\end{array}$ & Increase of the price $\mathrm{z} / \mathrm{m}^{3}$ & Final price (nett), zł/ $\mathrm{m}^{3}$ & Final price (gross $\left.{ }^{1}\right), \mathrm{z} z / \mathrm{m}^{3}$ \\
\hline $10 \%$ & 0.09 & 3.2 & 3.26 \\
\hline $30 \%$ & 0.11 & 3.03 & 3.28 \\
\hline $50 \%$ & 0.13 & 3.05 & 3.30 \\
\hline $100 \%$ & 0.18 & 3.10 & 3.35 \\
\hline $150 \%$ & 0.22 & 3.15 & 3.40 \\
\hline $200 \%$ & 0.27 & 3.20 & 3.45 \\
\hline $300 \%$ & 0.36 & 3.29 & 3.55 \\
\hline
\end{tabular}

1) VAT of $8 \%$ included

Source: own estimation

Table 9. Modeling of the demand reaction

\begin{tabular}{|c|c|c|c|c|}
\hline $\begin{array}{c}\text { Change in } \\
\text { unit fees }\end{array}$ & Price increase $\left(\mathrm{zt} / \mathrm{m}^{3}\right)$ & Change in demand $\left(\mathrm{hm}^{3} / \mathrm{y}\right)$ & $\begin{array}{c}\text { Change in annual withdrawal } \\
\left(\mathrm{hm}^{3} / \mathrm{y}\right)\end{array}$ & $\begin{array}{c}\text { \% change in annual } \\
\text { withdrawal }\end{array}$ \\
\hline $10 \%$ & 0.10 & -10.5 & -13.8 & $-0.7 \%$ \\
\hline $30 \%$ & 0.12 & -12.7 & -16.7 & $-0.8 \%$ \\
\hline $50 \%$ & 0.14 & -14.9 & -19.6 & $-1.0 \%$ \\
\hline $100 \%$ & 0.19 & -20.4 & -26.8 & $-1.3 \%$ \\
\hline $150 \%$ & 0.24 & -25.9 & -34.0 & $-1.7 \%$ \\
\hline $200 \%$ & 0.29 & -31.3 & -41.3 & $-2.0 \%$ \\
\hline $300 \%$ & 0.39 & 42.3 & -55.7 & $-2.7 \%$ \\
\hline
\end{tabular}

1) VAT of $8 \%$ included

Source: own estimation 


\section{Conclusions}

The process of modeling possible changes in water withdrawal included, hypothetically, radical changes of unit fees - up to $300 \%$. In extreme conditions the possibility of the reduction of water consumption and water intake using such an approach is very limited. It is possible of course to suggest challenging increases in fees, however an attempt in 2003 by Ministry of Environment to increase fees by $100 \%$ was cancelled a few months after its introduction. This gives a very good picture of the political affordability of the fee changes. The prices of water have been increased by $9 \%$ per year (the average growth for the period 2000-2011), so the expectation is that the unit fees can be increased by $100 \%$ or more seems to be unrealistic. Therefore the final conclusion is that the system of water intake fees in Poland is not - in the short and mid-term an effective instrument for water demand management. Therefore, the basic hypothesis has proven to be negative. There is no chance of using such fee changes as a tool for the adaptation to global climate change or water shortage that result from many other factors

A hypothetical increase of the unit fees by a factor of 2 caused a demand reaction of an approximate $2 \%$ drop in water intake. Every year approximately $25 \%$ of water withdrawal is lost or used for technical purposes. Therefore savings related to water loss appear to be fastest and easiest method of water demand management.
Bibliography

Analysis of the policy of water charges, 2009, MGGP, paper for National Water Board, not published, in Polish

Bartczak A., Kopańska A., Rączka J., 2009, Residential water demand in a transition economy: evidence from Poland, Water Science \& Technology: Water Supply, 9 (5), 509-516

Berbeka J, Berbeka K., 2002, Analysis of the cost of the implementation of selected, environmentally related EU directives on household expenditure in Poland, (in Polish), UKIE, Warsaw

Economic analysis of the new set of legal and financial rules related to the use of natural resources and services especially in water management, 2003, AK Consulting, Warsaw, report (in Polish) unpublished

Economic Analysis of Water Use for Water Authorities in Gdańsk. Part 1, 2012a, PectoreEco Szczecin, un-published paper

Economic Analysis of Water Use for Water Authorities in Krakow, 2012b, PiuConsulting, Krakow, unpublished paper

Economic Analysis of Water Use for Water Authorities in Szczecin, 2012c, PectoreEco, Szczecin, unpublished paper

Economic Analysis of Water Use in Poland, 2009, MGGP, paper for National Water Board, unpublished, in Polish

Environment Protection, Yearbooks for each year 2000-2011, CSO, Warsaw

Espey M., Espey J., Shaw W.D., 1997, Price elasticity of residential demand for water: A meta-analysis, Water Resources Research, 33 (6), 1369-1374 http://www.cena-wody.pl/index. 